\title{
Relationships between Static and Dynamic Balance and Anticipation Time, Reaction Time in School Children at the Age of 10-12 Years
}

\author{
Sinan Bozkurt ${ }^{1, *}$, Oya Erkut ${ }^{1}$, Orkun Akkoç ${ }^{2}$ \\ ${ }^{1}$ Faculty of Sports Science, Marmara University, Turkey \\ ${ }^{2}$ Faculty of Sports Science, Istanbul University, Turkey
}

Copyright $\bigcirc 2017$ by authors, all rights reserved. Authors agree that this article remains permanently open access under the terms of the Creative Commons Attribution License 4.0 International License

\begin{abstract}
The aim of this study is to investigate the relationship between anticipation time, reaction time and balance characteristics in school children at the age of 10-12 years. 11 males and 12 females, 23 students in total, studying at Istanbul Sancaktepe Ibn-i Sina Elementary School, whose average age was 11.06 years, average height was $142.78 \mathrm{~cm}$ and average weight was $37.6 \mathrm{~kg}$, voluntarily participated in the study. Height, body weight, anticipation time, reaction time, static balance and dynamic balance measurements were obtained from the subjects within the scope of the study. The descriptive statistics and the relationship between balance, anticipation time and reaction time parameters were investigated by using multiple correlations. The level of significance taken into account was $(\mathrm{p}<0.05)$. In conclusion, the significant relationships were found between auditory reaction time and $5 \mathrm{mph}$ anticipation time and static and dynamic balance $(p<0.05)$, between $3 \mathrm{mph}$ anticipation time and auditory reaction time and choice reaction time $(\mathrm{p}<0.05)$, between choice reaction time and simple reaction time and auditory reaction time $(\mathrm{p}<0.05)$. These perceptual motor skills could affect each other. It is suggested that physical education teachers should teach children to improve their anticipation time, balance and reaction time ability during the physical education lesson. They could place PE programs some special drills to improve these abilities.
\end{abstract}

Keywords Children, School, Anticipation Time, Dynamic and Static Balance, Reaction Time, Motor Control

\section{Introduction}

The ability to estimate the arrival time of a moving object from one point to a specific target point is called the anticipation time. Anticipation time is an important perceptual skill $[1,2,3,4]$. There are a lot of studies conducted on the relationship between anticipation time and age. Some of them have indicated that anticipation time develops during childhood (in the pre-school period) $[1,5,6$, 7, 8]. Haywood [5] found out in his study that the anticipation time of children between the ages of 6 and 8 years was worse when compared to the children between the ages of 11 and 13 years, and the anticipation time of children between the ages of 11 and 13 years was the same with young adults. These results indicate that anticipation time develops at best at the age of 11 years. Anticipation time experiences are the most important factors for anticipation time during childhood and youth periods $[9,10,11]$. Also there are some studies conducted on anticipation time at different speeds $[12,13,14]$.

Balance can be defined as the ability to keep the body's position on supporting area [15]. Person's ability to provide balance is a determinative factor in the development of other motor systems and forms a basis for a good performance [16]. Ferdjallah et al. [17] described balance as not only the integration of sensory inputs but also a complex motor skill involving the planning and application of flexible shapes of movement. Balance is examined as static balance and dynamic balance. The ability to provide body balance in a specific place or position is called static balance and the ability to provide body balance while moving is called dynamic balance. A postural control system which is necessary to provide balance requires the complex interaction of several structures such as visual, auditory, proprioceptive motor outputs in which many joints are coordinated. These systems develop during childhood. Until the age of 10 years, children are not as good at the control of static and dynamic balance as adults $[18,19]$.

Reaction time is the amount of time which elapses between the arrival of a signal which has developed suddenly and has been not anticipated and giving reaction to that signal $[20,21]$. In 2000, Tamer defined reaction time as the time elapsing between the emergence of a signal and the time 
of giving reaction to that signal [22]. Moreover, the reaction time is one of the important determinatives of time and opponent to take quick decisions. Stimuli can be auditory, visual or tactile. Reaction time is affected by factors such as age, gender, type of stimulus, habits and being on alert, exhaustion, alcohol, and nicotine, exercise level [23, 24].

As seen above, anticipation time of children between the ages of 11 and 13 years, balance of children between the ages of 10 years was the same with young adults. These perceptual motor skills develops in school age and also important for learning abilities. For example Atilgan [25] found that relationship between balance and two-hand coordination in her study.

As far as we know there are few study on relationship between anticipation time, reaction time and balance parameters in school children. Therefore, the aim of this study is to investigate the relationship between anticipation time, reaction time and balance characteristics in school children at the age of 10-12 years.

\section{Material and Methods}

\subsection{Participants}

11 males and 12 females, 23 students in total, studying at Istanbul Sancaktepe Ibn-i Sina Elementary School, whose average age was 11.06 years, average height was $142.78 \mathrm{~cm}$ and average weight was $37.6 \mathrm{~kg}$, voluntarily participated in the study. Participants are those who had no neurological diseases, vestibular visual disorders, lower extremity injuries or orthopaedic problems, and who do not do sports regularly apart from the physical education lesson of two hours in a week.

\subsection{Procedures}

Before the start of the study, the families of each subject were informed about the study and necessary permissions were obtained from the families and school administration. Height, body weight, anticipation time, reaction time, static balance and dynamic balance measurements were taken from the subjects within the scope of the study.

\subsection{Measurement Protocols}

The height of the subjects was measured with a metallic measuring tape in the sensitivity of $0,1 \mathrm{~cm}$ fixed on the scale and body weights were measured with a scale in the sensitivity of $0,1 \mathrm{~kg}$, barefoot and with light clothes on the subjects.

Anticipation time was measured with the Model 50575 Bassin Anticipation Timer device of Lafayette Instrument Company which is commonly used in the literature $[26,27$, 28, 29].

Children were asked to react by pushing the button of the device in their hand when the light moving with different mph was at the determined target point on the device. The 13th lamp in the second part of the device containing two parts was identified as the target point. The warning signal was given between 0.5 and 2 seconds between the first repetition and between repetitions. In the measurement of the anticipation time, the group repetition method consisting of 30 repetitions in total with 10 repetitions at $3 \mathrm{mph}, 5 \mathrm{mph}$, and $8 \mathrm{mph}$ was used and the average of 10 repetitions was obtained.

In the study, the visual and auditory reaction times of the participants were measured with the Newtest (model 1000) device. The visual reaction time was measured as simple (single light stimulus) and optional (four light stimulus) against the light stimuli. The auditory reaction time was measured as reacting to the audio stimulus coming from the device in the fastest way. After giving a test right to each subject for the visual and auditory reaction time, 10 measurements were made. The lowest and highest values of 10 measurements were not taken into consideration and the arithmetic mean of 8 values remaining was calculated.

The Y-Balance test was used to measure dynamic balance. Before starting the measurement, the feet of the subjects were placed behind the starting line. The subjects performed measurements barefoot. The subjects tried to reach the furthest point on the tiptoes of one foot without unbalancing. Before the measurement, 6 tests were conducted for each leg in the Anterior, Posterolateral and Posteromedial directions and then 3 measurements were obtained for each, and the longest access distance was used in the analysis. The total of 3 access directions was multiplied by 100 and divided into the multiplication of leg length $(\mathrm{cm})$ by 3 to find the balance score [30].

The balance performances of the subjects were measured by using the Balance Error Scoring System (BESS). In this test, the subjects were asked to maintain their test positions with their eyes closed and without taking any support for 20 seconds under 6 different conditions: 2 different grounds (hard floor and balance pad) and 3 positions (double leg, single leg and tandem).

A gym floor was used as a hard floor. A medium-density foam block of the size of $50 \times 41 \times 6 \mathrm{~cm}$ was used as a balance pad (Airex Balance Pad, Alcan Airex AG, CH-5643 Sins/Switzerland).

A 20-second-period was measured with a chronometer for each test condition. Each error made by the subjects in the 20 -second period was recorded as 1 error point. The maximum error point for each test condition is 10.6 different conditions accepted as error are as follows: (1) Raising hands from the upper part of the iliac, (2) opening eyes, (3) taking step, stumbling or falling, (4) making flexion or abduction of the hip joint at an angle more than $30^{\circ}$, (5) lifting the front part of foot or heel from the ground, (6) staying out of the test position for more than five seconds. The error points were calculated separately for each condition and the total error points were obtained by summing the points of 6 conditions. 
The scoring and reliability of this test were published by Riemann and Guskiewicz [31]. Before the test, the subjects were allowed to make enough repetitions to get used to different conditions.

\subsection{Statistical Analysis}

The descriptive statistics and the relationship between balance, anticipation time and reaction time parameters were investigated by using multiple correlations. The level of significance taken into account was $(\mathrm{p}<0.05)$.

The descriptive statistics (mean, standard deviation, minimum and maximum) were used. The relationship between static and dynamic balance, anticipation time and reaction time parameters was examined by using multiple correlations. The level of statistical significance was set top $\leq 0.05$. Statistical analyses were performed by using the Statistical Package for Social Sciences (SPSS version 15.0).

\section{Findings}

The findings of this study are presented in the following three tables. The mean and standard deviation values of the height, body weight, age and body mass index of the subjects are indicated in Table 1.

Table 1. Descriptive Characteristics of the Subjects

\begin{tabular}{|c|c|}
\hline $\mathrm{n}=23$ Characteristics & Mean \pm SD \\
\hline Height $(\mathrm{cm})$ & $142.75 \pm 8.14$ \\
\hline Body weight $(\mathrm{kg})$ & $37.60 \pm 8.21$ \\
\hline Age (years) & $11.12 \pm 0.50$ \\
\hline Body Mass Index $($ BMI $)$ & $18.47 \pm 3.92$ \\
\hline
\end{tabular}

Table 2. Balance, anticipation time and reaction time characteristics of the subjects

\begin{tabular}{|c|c|}
\hline $\begin{array}{c}\mathrm{n}=23 \\
\text { Characteristics }\end{array}$ & Mean $\pm \mathrm{SD}$ \\
\hline Static Balance Hard Floor (error count) & $4.30 \pm 3.46$ \\
\hline Dynamic Left (score) & $83.06 \pm 9.90$ \\
\hline Static Balance Pad (error count) & $9.82 \pm 4.43$ \\
\hline Dynamic Right (score) & $81.69 \pm 9.70$ \\
\hline 3 mph anticipation (sec) & $0.0671 \pm 0.04$ \\
\hline 5 mph anticipation (sec) & $0.0666 \pm 0.03$ \\
\hline 8 mph anticipation (sec) & $0.0625 \pm 0.01$ \\
\hline Simple reaction (sec) & $0.2995 \pm 0.13$ \\
\hline Auditory reaction (sec) & $0.3164 \pm 0.10$ \\
\hline Choice reaction (sec) & $0.5242 \pm 0.08$ \\
\hline
\end{tabular}

mph; mile/per hour, sec; second

The mean and standard deviation values of the static balance, dynamic balance, anticipation time (3-5-8 $\mathrm{mph}$ ), and simple, auditory, choice reaction times of the subjects are indicated in Table 2. When the averages of the results of two static balance error number measurements performed were examined, it was observed that children provided better balance on the hard floor (4.30) when compared to the balance pad (9.82). It was observed in the dynamic balance that the arithmetic means of the left foot dynamic balance measurements of the subjects (83.06) provided better results when compared to the arithmetic means of the right foot dynamic balance measurements (81.69). It was found out in the anticipation time results that the best results were $8 \mathrm{mph}$ (0.0625), $5 \mathrm{mph}(0.0666)$ and $3 \mathrm{mph}(0.0671)$, respectively. When the reaction time results were considered, it was observed that the best results were simple RT $(0.299)-$ auditory RT (0.316) and choice RT (0.524), respectively.

Table 3. Correlation Matrix of the subjects' balance, anticipation time, and reaction parameters

\begin{tabular}{|c|c|c|c|c|c|c|c|c|c|c|}
\hline & SBHf & DBLf & SBP & DBRf & $3 \mathrm{mph}$ & $5 \mathrm{mph}$ & $8 \mathrm{mph}$ & SR & $\mathbf{A R}$ & CR \\
\hline $\begin{array}{c}\text { Static Balance } \\
\text { Hard Floor (SBHf) }\end{array}$ & 1 &,- 309 &, $665^{* *}$ &,- 308 & ,263 &, $414^{*}$ & ,257 & ,348 &, $437^{*}$ & ,361 \\
\hline $\begin{array}{l}\text { Dynamic Balance } \\
\text { Left Foot (DBLf) }\end{array}$ & & 1 &,- 167 &, $846^{* *}$ &,- 401 &,$- 503^{*}$ &,- 057 &,- 010 &,$- 487^{*}$ &,- 388 \\
\hline $\begin{array}{l}\text { Static Balance } \\
\text { Pad (SBP) }\end{array}$ & & & 1 &,- 204 & ,269 & ,308 &,- 064 & ,391 &, $439^{*}$ & ,490* \\
\hline $\begin{array}{l}\text { Dynamic Balance } \\
\text { Right Foot(DBRf) }\end{array}$ & & & & 1 &,- 359 &,$- 482^{*}$ &, 016 & ,049 &,$- 501^{*}$ &,- 266 \\
\hline $\begin{array}{c}3 \mathrm{mph} \\
\text { Anticipation } \\
\end{array}$ & & & & & 1 & ,335 & ,280 & ,271 &, $734^{* *}$ & ,645 \\
\hline $\begin{array}{c}5 \mathrm{mph} \\
\text { Anticipation }\end{array}$ & & & & & & 1 & ,219 &, 052 &, $432^{*}$ &, 283 \\
\hline $\begin{array}{c}8 \mathrm{mph} \\
\text { Anticipation } \\
\end{array}$ & & & & & & & 1 & , 177 & ,230 & ,404 \\
\hline $\begin{array}{c}\text { Simple } \\
\text { Reaction (SR) }\end{array}$ & & & & & & & & 1 & ,428* &, $528^{* *}$ \\
\hline $\begin{array}{c}\text { Auditory } \\
\text { Reaction (AR) }\end{array}$ & & & & & & & & & 1 &, $592^{* *}$ \\
\hline $\begin{array}{c}\text { Choice } \\
\text { Reaction (CR) } \\
\end{array}$ & & & & & & & & & & 1 \\
\hline
\end{tabular}

${ }^{* *} \mathrm{p} \leq 0.01,{ }^{*} \mathrm{p} \leq 0.05$ 
The correlation results of the participants' static balance (hard floor and balance pad), dynamic balance (right and left foot), anticipation time (3-5-8 $\mathrm{mph})$ and reaction time (simple, auditory and choice) are presented in Table 3.

A significant relationship was found between $5 \mathrm{mph}$ Anticipation Time and $\operatorname{SBHf}(\mathrm{r}=0.414 ; \quad \mathrm{p}=0.005)$, $\operatorname{DBLf}(\mathrm{r}=-0.503 ; \quad \mathrm{p}=0.005), \quad \operatorname{DBRf}(\mathrm{r}=-0.482 ; \quad \mathrm{p}=0.005)$, auditory reaction time $(\mathrm{r}=0.432 ; \mathrm{p}=0.005)$. When the results of the anticipation time were examined, $3 \mathrm{mph}$ anticipation time was found to be highly related to the auditory reaction time $(\mathrm{r}=0.734 ; \mathrm{p}=0.001)$ and choice reaction time $(\mathrm{r}=0.645$; $\mathrm{p}=0.001)$. A significant relationship was identified between choice reaction time and simple reaction time $(\mathrm{r}=0.528$, $\mathrm{p}=0.001)$, auditory reaction time $(\mathrm{r}=0.592, \mathrm{p}=0.001)$. There was also a relationship between choice reaction time and Static Balance Pad ( $\left.r \_0.490, p=0.005\right)$. According to the results of dynamic and static balance, a relationship was determined between auditory reaction time and SBHf $(\mathrm{r}=0.437 ; \mathrm{p}=0.005), \quad \operatorname{DBLf}(\mathrm{r}=-0.487 ; \mathrm{p}=0.005), \quad$ SBP $(\mathrm{r}=0.439 ; \mathrm{p}=0.005), \operatorname{DBRf}(\mathrm{r}=-0.501 ; \mathrm{p}=0.005)$.

\section{Discussion}

Upon examining the literature, it is observed that while there are studies in which visual and auditory reaction times are addressed in various sports branches with different abilities, there are a limited number of studies examining the relationship between static and dynamic balance, and anticipation time and reaction time. At the same time, there are a limited number of studies on the relationship between reaction time and balance in children without sports past. Atilgan[25]found a correlation between the two-hand coordination and balance, strength, vertical jump and certain anthropometric parameters $(\mathrm{p}<0.05)$ while there was no correlation between balance parameter (SB-DB) and choice reaction time in male children at the age of 9 years $(p>0.05)$, and stated that doing upper extremity coordination exercises in sports training programs can make a positive contribution to balance development in order to increase static and dynamic balance developments of children [25]. Arslanoglu et al.[32] could not find a significant relationship between the visual and auditory reaction times and the right and left foot balance scores in the study conducted with badminton players.

In our study, a positive relationship was found between the hard floor and balance pad static balance, the right foot and left foot dynamic balance measurements, and auditory reaction time $(p<0.05)$. Hatzataki et al. [33] studied the correlation relationship between balance parameters, perceptual, cognitive and motor skills, and dynamic and static balance in their studies and they found a relationship between the static balance parameters, and reaction time and depth perception tests. The results of these studies are parallel with our study.

It was observed that the best results of anticipation time were 8,5 and $3 \mathrm{mph}$, respectively. These results indicate that the anticipation time performance decreases at low speeds. Rudisill and Jackson [34] state that it is harder to estimate movements at low and high speeds when compared to the medium speed.

Moreover, when the relationship between anticipation time and balance and reaction time was examined, a relationship was found between $3 \mathrm{mph}$, and auditory RT and choice RT; and between $5 \mathrm{mph}$ and auditory RT. A relationship was found between the hard floor static balance and $5 \mathrm{mph}$ anticipation time, and between the right and left foot dynamic balance and $5 \mathrm{mph}$ anticipation time.

Bozkurt [35] found a significant relationship between the visual reaction time and anticipation time in the study conducted with football players at the average age of 13.5 years $(\mathrm{p}<0.05)$.

\section{Conclusions}

The results of the current study show that a significant relationship was found between auditory reaction time and 5 mph anticipation time and static and dynamic balance $(\mathrm{p}<0.05)$, between anticipation time $(3 \mathrm{mph})$ and auditory reaction time and choice reaction time $(p<0.05)$, between choice reaction time and simple reaction time and auditory reaction time $(\mathrm{p}<0.05)$. These perceptual motor skills affect each other as seen above. Therefore, it is suggested that physical education teachers should teach children to improve their anticipation time, balance and reaction time ability during the physical education lesson. They could place PE programs some special drills to improve these abilities. Further studies are recommended to clarify the relationship between the balance, anticipation time and reaction time parameters.

\section{Acknowledgements}

The authors thank Gulsum Terzi, Sevki Guneri and Yahya Yildirim for their assistance in this study.

\section{REFERENCES}

[1] Robyn Kim, Genevieve Nauhaus, And Kuba Glazek Development Of Coincidence-anticipation Timing In A Catching Task Perceptual \& Motor Skills: Physical Development \& Measurement 2013, 117, 1, 319-338. (C) Perceptual \& Motor Skills 2013

[2] Gabbet, T., Rubinoff, M., Thorburn, L., \& Farrow, D. (2007). Testing And training anticipation skills in softball fielders. International Journal of Sports Science \& Coaching, 2, 15-24.

[3] Yufu M. Tanaka Effects of Explicit and Implicit Perceptual Training on Anticipation Skills of Novice Baseball Players 
Asian Journal of Exercise \& Sports Science 2011 Vol. 8 (No.1).

[4] Leila Nuri, Azadeh Shadmehr, Nastaran Ghotbi \& Behrouz Attarbashi Moghadam (2013) Reaction Time and Anticipatory Skill of Athletes in Open and Closed Skill-Dominated Sport. European Journal of Sport Science. 13(5): 431-436.

[5] Haywood, K. M. (1980) Coincidence-anticipation accuracy across the life span. Experimental Aging Research, 6 (5), 451461.

[6] Thomas, J. R., Gallagher, J. D., \&Purvis, G. J. (1981) Reaction time and anticipation time: effects of development. Research Quarterly for Exercise and Sport, 52 (3), 359 - 367.

[7] Williams, K. (1985) Age differences on a coincident anticipation task: influence of stereotypicor "preferred" movement speed. Journal of Motor Behavior, 17 , $389-410$

[8] Benguigu1, N., Broderıck, M., \&Ripoll, H. (2004) Age Differences in Estimating Arrival time Neuroscience Letters, 3 (69), 197 - 202.

[9] Brady, F. (1996) Anticipation Of Coincidence, Gender, And Sports Classification. Perceptual \& Motor Skills, 82 (1), 227 239.

[10] Ripoll, H., \& Latırı , I. ( 1997 ) Effect of expertise on coincident-timing accuracy in a fast ball game. Journal of Sports Sciences, 15, 573 - 580.

[11] Ak, E., \&Kocak, S. (2010). Coincidence-Anticipation Timing And Reaction Time In Youth Tennis and Table Tennis Player. Perceptual and Motor Skills, 879-887.

[12] Michael, J., Duncan, Michelle Stanley, Mike Smith, Michael J. Price, and Sheila Leddington Wright Coincidence Anticipation Timing Performance during an Acute Bout of Brisk Walking in Older Adults: Effect of Stimulus Speed Hindawi Publishing Corporation Neural Plasticity ArticleID210213Received November2013

[13] Fleury, M., \& Bard, C. (1985). Age, Stimulus Velocity And Task Complexity As Determiners Of Coincident Timing Behaviour. Journal Of Human Movement Studies, 11, $305 \_317$.

[14] Sanders, G. (2011). Sex differences in coincidence anticipation timing (CAT): A review. Perceptual and Motor Skills, 112, 61 90. doi: 10.2466/04.25.PMS.112.1.61-90

[15] SpirdusoWw., Balance, Posture And Locomotion. in: Physical Dimensions of Aging. Human Kinetics, Champaing, Illionis 1995, Pp 152-185

[16] Aksu, S., Denge Eğitiminin Etkilerinin Postüral Stres Testi ile Değerlendirilmesi. Hacettepe Üniversitesi Sağlık Bilimleri Enstitüsü Bilim Uzmanlığ Tezi, Ankara, 1994

[17] Ferdjallah, M., Harris, G.F., Smith, P., Wertsch, J.J., “Analysis Of Postural Control Synergies During Quiet Standing in Healthy Children And Children With Cerebral Palsy", Clinical Biomechanics, 17, 203-210, 2002.

[18] Muratlı, S., Çocuk ve Spor-Antrenman Bilimi Işı̆̆ı Altında, Bağırgan Yayımevi, Ankara, 1997.

[19] Rival,C., Ceyte, H., \& Olivier, I. (2005) Developmental changes of static standing balance in children, Neuroscience Letters, 376 (2005) 133-136.
[20] Schmidt, R.,A. (1988). Motor control and learning. Champaign, lllinois, Human Kinetics Publishers Inc., Second ed., 64-65.

[21] J. Shelton ve G. Kumar, "Comparison between Auditory and Visual Simple Reaction Times," Neuroscience\& Medicine, Vol. 1 No. 1, 2010, pp. 30-32. doi:10.4236/nm.2010.11004

[22] Tamer K. Sporda Fizyolojik Fiziksel Performansın Ölçülmesi ve Değerlendirilmesi 2. Baskı, Ankara: Bağırgan Yayınevi, 2000: $32-184$

[23] Pashler, H. (1991). "Shifting visual attention and selecting motor responses: distinct attentional mechanisms" J. ExpPsychol Hum Per- cept Perform. 17(4), 1023-40.

[24] Kosinkski J. "Literature Review On Reaction Time”. Clemson University. May 2015.

Http://Biae.Clemson.Edu/Bpc/Bp/Lab/110/Reaction.Htm (20.05.2015)

[25] Atılgan O. E. (2012). Relationships Between Perceptual-Motor Skills And Postural Balance In Nine Years Old Boys. Educational Research And Reviews Vol. 7(24), Pp. 517-525,

[26] Magill, R. A., Chamberlin, C. J., \& Hall, K. G. (1991) Verbal knowledge of results as redundant information for learning an anticipation timing skill. Human Movement Science. 10, 485-507.

[27] Rudisill, M. E., \& Jackson, S.A. (1992). Theory \& Application of Motor Learning-Lab Manuel. Lafayette Instrument Company. 78.

[28] Williams, L. R.T., Katene, W. H., Fleming, K., \& Bennett, S. J. (2002) Coincidence timing of a tennis stroke: effect of age, skill level, gender, stimulus velocity, and attention demand. Research Quarterly for Exercise and Sport, 73, 28-37.

[29] Bozkurt, S. (2004) The Study of Relationship between Creativity and Multiple Intelligence and Creativity in the Sports of Soccer. Doctoral Thesis, Marmara University Institute of Medical Sciences, Istanbul.

[30] Plisky PJ, Rauh MJ, Kaminski TW, Underwood FB. J Orthop Sports Phys Ther. 2006 Dec; 36(12): 911-9.

[31] Riemann, B.L., and Guskiewicz, K.M., (2000). Effects of Mild Head Injury on Postural Stability as Measured Through Clinical Balance Testing. J Athl Train, 35, pp: 19-25.

[32] Arslanoğlu E, Arslanoğlu C, Aydoğmuş M, Şenel Ö (2010). Badmintoncularda Reaksiyon Zamanı ve Denge Ilişkisi. Niğde University J. Phys. Edu. Sport Sci. 4:131-136.

[33] Hatzataki V, Zisi V, Kollias I, Kioumourtzoglou E (2002). Perceptual- motor contributions to static and dynamic balance control in children. J. Motor Behav. 34(2):161-170.

[34] Rudisill, M. E., \& Jackson, S.A.(1992). Theory \& Application of Motor Learning-Lab Manuel. Lafayette Instrument Company. 78.

[35] Bozkurt, S. (2015) Perceptual and Motor Components Of Young Football Players. 1st Scientific Conference on Motor Skill Acquisition. Kisakallio, Finland. November 2015. 